\title{
Effect of Vapour Absorption Enhancement in Solar-Heat Driven Air-Conditioning System
}

\author{
Papia Sultana, N. E. Wijeysundera, J. C. Ho, C. Yap, and T. K. Chang
}

\begin{abstract}
The solar-heat driven air-conditioning system has strong potential for significant primary energy savings. For most applications, the system involves $\mathrm{Li}$-Br-water absorption chillers, which are suitable for large building applications. For absorption chillers to be used in small residential buildings, the reduction of the chiller system footprint is critical. In the present study focus has been given to design a vapour-absorption cooling system with improved transport phenomena using film-inversion techniques. The film-inverting absorber has resulted in the enhancement of vapour absorption rate by 83-95 percent more than a conventional falling film-tubular absorber based on numerical simulation data. The proposed design has the potential to increase Coefficient of Performance (COP) of a single-effect vapour absorption system $160 \%$ higher than that of a conventional vapour-absorption system. It could also reduce the foot-print of the entire vapour absorption system especially for low-grade-heat driven applications. At least $10^{\circ} \mathrm{C}$ temperature reduction has been achieved in maintaining the same condensing pressure. Moreover, a smaller area is needed to harvest hot water for a solar-heat driven air-conditioning system. Also there has been at least $65 \%$ reduction of the collector area needed per $\mathrm{kW}$ cooling energy.
\end{abstract}

Index Terms-Coefficient of Performance

(COP) film-inverting, solar-heat-driven, vapour absorption.

\section{INTRODUCTION}

Recent studies have acknowledged that energy consumption per unit area of buildings is relatively high [1]. One of the main challenges of designing a green building is to reduce energy consumption in its high energy intensive areas such as air-conditioning. In order to improve energy conservation of buildings, engineers are focusing on design improvement and exploit the opportunities to integrate cooling system driven by renewable energy sources. With regard to this integration approach, solar energy driven absorption chillers have already been used in many demonstration projects. According to Balaras et al. [2] solar air-conditioning has a strong potential for significant primary energy savings. In most applications, Li-Br-water absorption chillers are used. Studies have shown that most absorption cooling systems are suitable for large-building applications with capacities more than $100 \mathrm{~kW}$. Small capacity $(<100 \mathrm{~kW})$

Manuscript received September 25, 2013; revised January 16, 2014.

Papia Sultana and T. K. Chang are with the School of Engineering, Republic Polytechnic, Singapore (e-mail: papia_sultana@ rp.edu.sg, chang_teck_keng@rp.edu.sg).

N. E. Wijeysundera was with Mechanical Engineering Department, National University of Singapore (e-mail nwijeysundera@gmail.com).

J. C. Ho and C. Yap are with Mechanical Engineering Department, National University of Singapore (e-mail: mpehojc@nus.edu.sg, cyap@nus.edu.sg). absorption chillers are relatively rare in the market [1]. If absorption chillers are to be solar driven for residential buildings application, reduction of the system foot-print becomes more challenging. Because the surface area needed for the solar collector for generating hot water in the range of 65 to $85^{\circ} \mathrm{C}$ is quite large [3]. Hence focus should be given to designing absorption chiller which has the potential to work under low-temperature and pressure at the generator so that solar collector size can be reduced. Driven from such background, the present study is focused on developing an improved absorber design which is able to increase the COP of absorber by reducing the overall footprint of absorption cooling system while having the potential to be driven from low grade heat by lowering down generator working temperature. This work followed the concept of film-inverting absorber as implemented by Islam et al. [4] which shows significant improvement of vapour absorption rate. In the present study a new film-inverting absorber has been explored which depends on the Coanda-effect to create film-inversion. The Coanda-effect has been widely used in many fluid-dynamics based appliances such as air-craft and even air-diffusion devices in the air-conditioning industry. As proposed in this paper, the eccentric or off-centered positioning of the tubes in multiple arrays would create the opportunity to reduce the size of the absorber by producing greater cooling effect from a smaller footprint of absorption chiller.

\section{A. Role of Absorbers in Vapour Absorption System}

The absorber is usually the largest and the most expensive component of the absorption cooling system. It is a place where the low pressure refrigerant vapour or the absorbate is absorbed in an absorbent solution. In practical absorbers shown in Fig. 1, a thin film of liquid solution composed of absorbent and absorbate flows down over the absorber surface. The film is in contact with stagnant vapour of absorbate at a constant pressure different from the equilibrium vapour pressure of the inlet solution. As a result of this difference, mass transfer of absorbate takes place at the liquid-vapour interface. The absorbed absorbate diffuses into the liquid film. The heat generated in the absorption process that is the heat of absorption flows through the film to the external coolant. The purpose of the coolant is to sustain the absorption process by continually removing the heat released. The performance of the vapour absorption system is greatly dependent on the rate of absorption of the refrigerant vapour into the absorbent liquid. Lower absorption rate can reduce the flow of refrigerant which in effect can reduce the overall system performance. So a lower coefficient of performance (COP) of the absorption refrigeration machines is mainly due to the lower performance of the absorber. Another major 
feature of vapor absorption machines is the absorber being the most expensive part of the system mostly due to its size, weight and complexity of the absorption process. It is the size of the absorber which greatly affects the heat and mass transfer processes during the cycle operation. If the transport processes are improved, greater reduction in the absorber size can be achieved and hence a reduction of overall system cost.

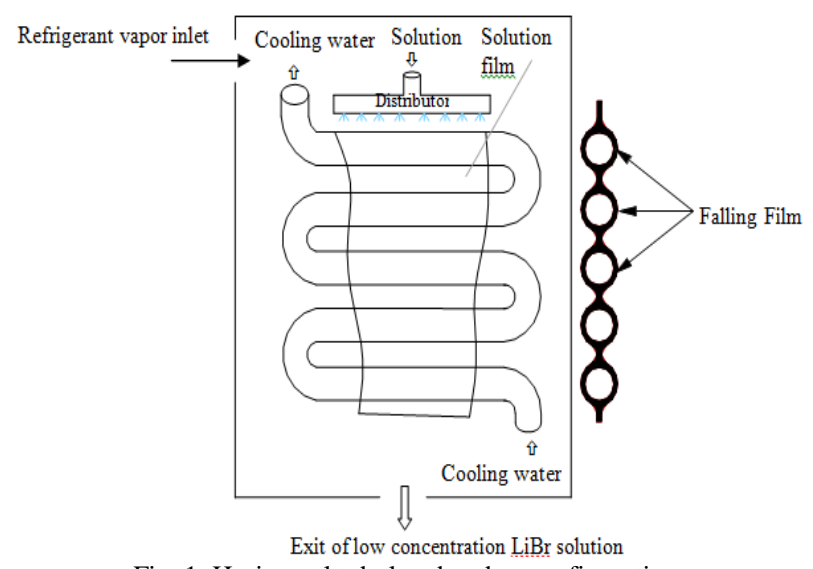

Fig. 1. Horizontal tubular absorber configuration.

\section{B. The Coanda Effect}

The Coanda Effect is the tendency of a moving fluid, liquid or gas, to attach itself to a curved surface and flow along it. It means that when one side of a falling jet is close to a large solid curved surface, a partial vacuum is created between the jet and the surface, as a consequence of which, the jet tends to attach itself to the surface [5]. The Coanda Effect has many applications especially in the development of various fluid-flow devices. In the present study, the Coanda Effect is used to develop a film-inverting absorber. A thin film of liquid, $\mathrm{m}_{\mathrm{si}}$ flowing down the side of a tube turns around the opposite side of a second tube when the later is brought to touch the film. The Coanda effect actually turns the liquid film between two round tubes arranged vertically as shown in Fig. 2. Just after turning on the opposite side of the second tube, the exposed surface of the film flowing over the first tube becomes the inner surface of the film over the second tube and vice versa. Using a number of tubes in an array, repeated film surface reversal, which is the main characteristic of a film-inverting absorber, can be achieved.

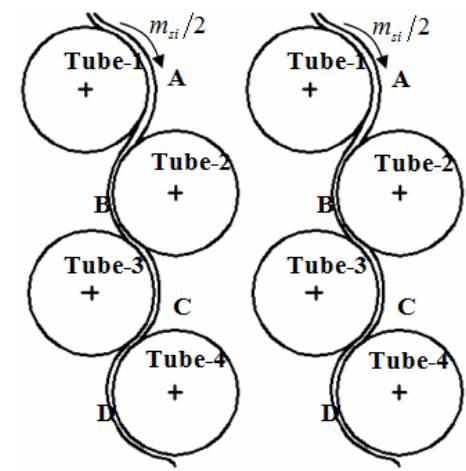

Fig. 2. Coanda-effect based film-inverting absorber in multiple columns.

\section{EXPERIMENTAL SET UP}

An experimental study was undertaken to investigate the film-inverting hydrodynamics. Six hollow copper tubes of outer diameter $22 \mathrm{~mm}$ and length $240 \mathrm{~mm}$ have been arranged with their centers in two vertical planes. The distributor was placed above the top-most tube in such way that the flow was only distributed to one side of the top most tube. Before starting the experiments, the test tubes are cleaned thoroughly with sand papers so that surface roughness is increased to provide better surface wetting. The radial gap between two neighboring tubes, which is nearly equal to the film thickness, is set by trial and error. The test tubes are adjustable from the sides which provide the required flexibility to change the gap. The experiment is normally started with a higher solution flow rate to ensure better surface wetting. The flow rate is then gradually decreased and the film flow is observed closely. At the desired flow rate when the film flow alternates from one tube to the next, the screws shown in Fig. 3 are tightened to ensure the stability of the tube assembly. At different flow conditions, the flow pattern is recorded in video with a digital video camera, the purpose of which is to obtain the qualitative behaviour of the flow in the absorber. The experiments were carried out with water as the working fluid.

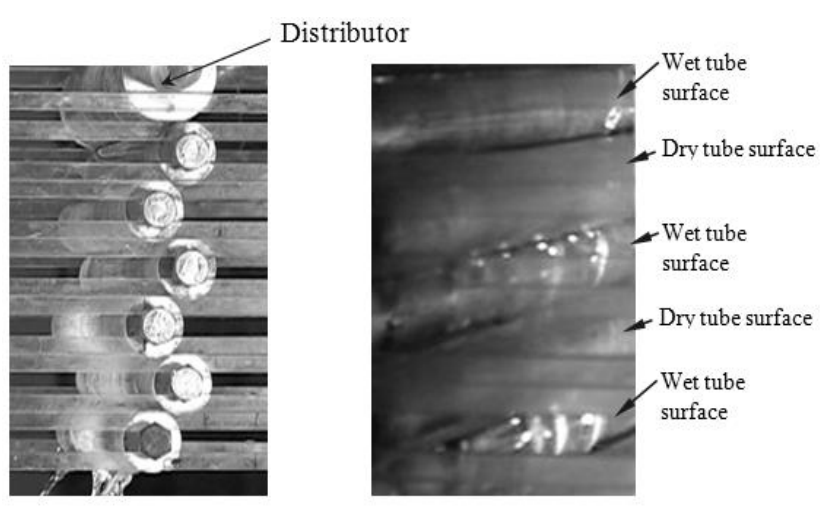

Fig. 3. Film-inversion mechanism using single array of tubes.

\section{A. Flow Observations}

As shown in Fig. 3, the alternate flow surfaces of the tubular arrangement are clearly noticeable. The flow is introduced at the topmost tube from a distributor which is placed on one side of the top tube. It is interesting to observe from Fig. 3 that the film flowing down one side of the tube turns around the bottom of the tube and leaves on the opposite side as jets. However in the presence of another tube, positioned slightly off the vertical plane of the first tube and touching the liquid film, the film turns around the second tube. As the film turns around the nearest curved surface, it travels around the alternate sides of the tubes if a bank of tubes is constructed. The radial gap between any two tubes is nearly equal to the film thickness which is sufficient for the liquid film to turn and flow without any obstruction. The wet surface of the liquid film falling down the first tube can be seen clearly in the Fig. 3. Because the film makes the turn on the opposite side of the second tube, after leaving the first tube, the dry surface of the second tube is observed. In the third tube, where the film turns around the opposite side shows a wet surface in the image. The wet surfaces are identifiable in the figure as reflecting surfaces in the presence of illuminating light. Thus for the bank of six tubes, the alternate film inversion is achieved without the use of guide vanes. The effect of varying solution flow rate during film-inversion was also investigated. Fig. 4 shows the film flow over the tubes at 
three different flow rates. At higher flow rate, the flow surface over the tubes is wavier though the waviness diminishes if the flow rate is gradually decreased. Presence of surface waves in the form of rings especially at the higher flow rate may prevent uniform distribution of the flow. It is therefore desirable that the gap between the tubes be such that the film flows with uniform surface wetting and without any flow obstruction. If the tube gap is too large film inversion will not occur because the adjacent tube losses contact with the liquid film. Thus an optimum tube gap has to be provided to ensure film flow without obstruction but sufficiently narrow to cause the Coanda Effect.
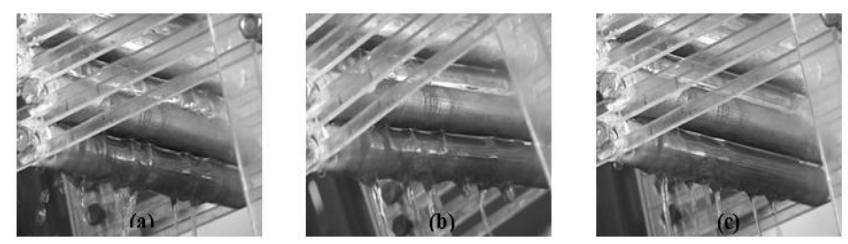

Fig. 4. Film flow at three design flow rates (a) $0.022 \mathrm{~kg} . \mathrm{s}^{-1}$ (b) $0.016 \mathrm{~kg} . \mathrm{s}^{-1}$ (c) $0.008 \mathrm{~kg} . \mathrm{s}^{-1}$.

\section{EFFECT ON SYSTEM PERFORMANCE}

In order to explain the importance of film-inversion in a falling film absorber, numerical models have been developed for both with and without film-inversion which has been stated in [6], [7]. Operating conditions have been depicted in Table I for fixed solution inlet temperature at the absorber, $T_{s i}$ $=39.8^{\circ} \mathrm{C}$ and solution inlet concentration at the absorber, $w_{s i}$ $=0.604$ respectively. As shown in Table II, vapour enhancement due to film inversion has been found to be 83-95 percent whereas the vapour mass flux enhancements measured in the actual experiments of [8] were 88-102 percent. The numerical results verify the significant performance improvement due to film inversion.

TABLE I: EXPERIMENTAL OPERATING CONDITIONS OF ISLAM ET AL. [8]

\begin{tabular}{|c|c|c|c|c|}
\hline $\begin{array}{l}\text { Set } \\
\text { no }\end{array}$ & $\begin{array}{l}\text { Cooling water } \\
\text { inlet temperature } \\
\text { at the absorber } \\
\mathrm{T}_{\mathrm{wi}}\left[{ }^{0} \mathrm{C}\right]\end{array}$ & $\begin{array}{l}\text { Cooling } \\
\text { water flow } \\
\text { rate } \\
{\left[\mathrm{kg} . \mathrm{s}^{-1}\right]} \\
\end{array}$ & $\begin{array}{c}\text { Mass flow rate } \\
\text { of solution } \\
{\left[\mathrm{kg} \cdot \mathrm{m}^{-1} \mathrm{~s}^{-1}\right]}\end{array}$ & Pressure \\
\hline 1 & 26.53 & 0.0887 & 0.0595 & 2.15 \\
\hline 2 & 26.58 & 0.0887 & 0.0446 & 2.08 \\
\hline 3 & 29.43 & 0.0887 & 0.0446 & 2.08 \\
\hline 4 & 26.45 & 0.0887 & 0.0298 & 2.21 \\
\hline 5 & 29.3 & 0.0887 & 0.0298 & 2.21 \\
\hline
\end{tabular}

TABLE II: ABSORPTION PERFORMANCE OF FILM-INVERTING ABSORBERS

\begin{tabular}{cccc}
\hline \hline $\begin{array}{c}\text { Set } \\
\text { no }\end{array}$ & $\begin{array}{c}\text { Average mass flux } \\
\text { with film inversion } \\
{\left[\mathrm{kg} \cdot \mathrm{m}^{-2} \cdot \mathrm{s}^{-1}\right]}\end{array}$ & $\begin{array}{c}\text { Average mass flux } \\
\text { without film inversion } \\
{\left[\mathrm{kg} \cdot \mathrm{m}^{-2} \cdot \mathrm{s}^{-1}\right]}\end{array}$ & $\begin{array}{c}\text { Percent change } \\
\text { with film } \\
\text { inversion } \\
{[\%]}\end{array}$ \\
\hline 1 & 0.004702 & 0.002522 & 86.4 \\
\hline 2 & 0.004123 & 0.002242 & 83.9 \\
\hline 3 & 0.004082 & 0.002229 & 83.1 \\
\hline 4 & 0.004473 & 0.002296 & 94.8 \\
\hline 5 & 0.004390 & 0.002259 & 94.4 \\
\hline
\end{tabular}

To further understand the importance of film-inverting absorber to improve the vapour absorption cooling system performance, a single-effect vapour absorption cycle has been analyzed. The system diagram has been shown in Fig. 5 . Numerical simulation has been performed for 24 bank of horizontal tubes arranged both in conventional configuration and in film-inverting configuration. From the numerical simulation results, the inlet and outlet conditions of LiBr-solution at the absorber has been plotted in Fig. 6 to identify the equilibrium conditions for the desorption to take place in the generator.

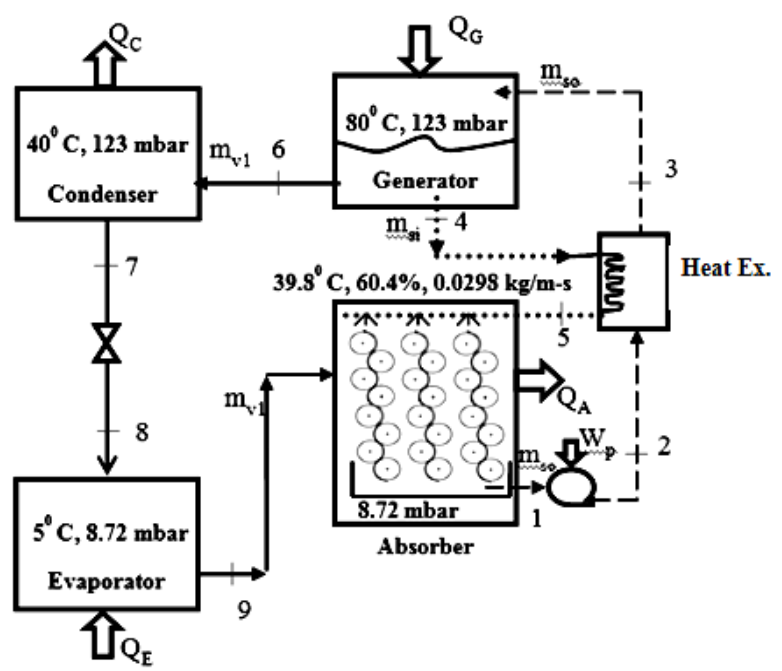

Fig. 5. Single-effect vapour absorption system based on proposed design; + ) $\mathrm{H}_{2} \mathrm{O}$ as refrigerant, (- - -)Weak $\mathrm{LiBr}$ solution, ( ........) Strong $\mathrm{LiBr}$ solution, $\mathrm{m}_{\mathrm{v} 1}=$ vapour absorption rate or refrigerant flow rate, $\mathrm{m}_{\mathrm{si}}=$ mass flow of solution at absorber inlet, $\mathrm{m}_{\mathrm{so}}=$ mass flow of solution at absorber outlet.

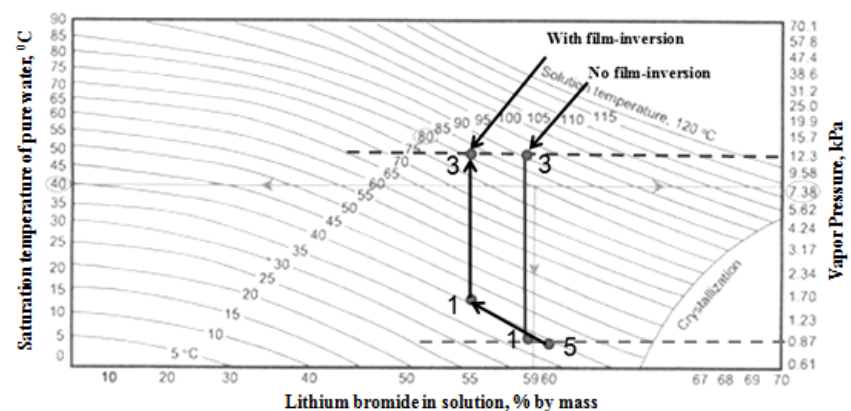

Fig. 6. Comparison of equilibrium temperature of desorption in the generator based on the performance of with and without film-inverting absorber.

Under the same operating conditions of [8], film-inverting absorber has shown at least $10{ }^{\circ} \mathrm{C}$ temperature reduction in order to maintain same condensing pressure. The significance of this equilibrium solution vapour temperature reduction at the generator indicates that performance enhancement due to film-inversion is capable of lowering down the operating temperature of the generator. As a result, low grade heat $\left(<80{ }^{\circ} \mathrm{C}\right)$ has great potential to drive this absorption cooling system if it is possible to further reduce the condensing pressure. In the film-inverting absorber, due to the lower concentration of $\mathrm{LiBr}$ in the solution at the entrance of the generator, equilibrium vapor-pressure required to separate the water from the weak solution is lowered. Hence vapor can leave the generator at a lower pressure and subsequently condenser operating pressure can be lowered. Based on calculated heat input at the generator, $\mathrm{Q}_{\mathrm{G}}$ and cooling effect, $\mathrm{Q}_{\mathrm{E}}$ for this current application, film inverting absorber could provide COP at least $160 \%$ more than the conventional system. This is mainly due to the vapour absorption 
enhancement in the absorber and the associated reduction of condenser pressure. Data has been depicted in Table III. The procedure of COP calculation has been undertaken from Balany [9].

TABLE III: SYSTEM PERFORMANCE ENHANCEMENT

\begin{tabular}{|c|c|c|c|c|}
\hline & $\begin{array}{c}\text { Heat } \\
\text { transfer at } \\
\text { the } \\
\text { generator, } \\
\mathrm{Q}_{\mathrm{G}} \\
{[\mathrm{kW}]}\end{array}$ & $\begin{array}{c}\text { Cooling effect } \\
\text { at the } \\
\text { evaporator, } \\
\mathrm{Q}_{\mathrm{E}} \\
{[\mathrm{kW}]}\end{array}$ & $\begin{array}{l}\mathrm{COP} \\
{\left[\mathrm{Q}_{\mathrm{E}} /\right.} \\
\left.\mathrm{Q}_{\mathrm{G}}\right]\end{array}$ & $\begin{array}{l}\% \text { Improvement } \\
\text { of COP due to } \\
\text { film inversion }\end{array}$ \\
\hline $\begin{array}{l}\text { With film } \\
\text { inversion }\end{array}$ & 2.29 & 1.49 & 0.65 & \multirow{2}{*}{$160 \%$} \\
\hline $\begin{array}{l}\text { Without } \\
\text { film } \\
\text { inversion }\end{array}$ & 2.27 & 0.567 & 0.25 & \\
\hline
\end{tabular}

\section{EFFECT ON SOlAR Hot WATER SYSTEM}

A flat plate solar-collector model has been used to estimate the area needed to harvest solar-heat to drive the absorption system. The amount of heat energy needed to harvest is shown as $\mathrm{Q}_{\mathrm{G}}$ in Table III. The average temperature needed to initiate desorption in the generator is measured from Fig. 6 for both with and without film inverting absorber. Following formula have been used to determine the required collector area:

$$
\begin{aligned}
& T_{a v}=\left(T_{G}+T_{i n}\right) / 2 \\
& Q_{\text {loss }}=F A U\left(T_{a v}-T_{a m b}\right)
\end{aligned}
$$

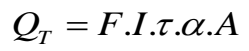

$$
\begin{aligned}
& Q_{G}=m_{w} c_{p w}\left(T_{G}-T_{i n}\right) \\
& \eta=Q_{G} /\left(Q_{T}-Q_{\text {loss }}\right)
\end{aligned}
$$

In the above formulas, $T_{a v}, T_{G}$ and $T_{i n}$ are defined as average collector fluid temperature, water temperature entering to the generator and water temperature at the inlet of the solar collector respectively. $Q_{\text {loss }}, Q_{T}$ and $Q_{G}$ are heat loss from the solar collector to the ambient, total available energy at the solar collector and actual energy harvested by the solar collector respectively. $I, F$ and $U$ are solar irradiation, collector heat removal efficiency and heat loss coefficient per degree of temp difference respectively. $\tau, \alpha$ and $\eta$ are transmissivity of solar collector material, thermal absorptivity of solar collector and thermal efficiency of solar collector respectively. $m_{w}, c_{p w}$ are the mass flow rate of water through the solar collector and specific heat of water respectively.

Substituting (2)-(4) in (5), collector area is expressed as:

$$
A=\frac{Q_{G}}{\eta\left[F . I . \tau . \alpha-F U\left(T_{a v}-T_{a m b}\right)\right]}
$$

Using (6) with necessary inputs of various constants, average area needed per unit cooling effect has been determined. Table IV shows the calculation details. After comparison, film-inverting absorber has shown $65 \%$ reduction in the required solar collector area per unit $\mathrm{kW}$ of cooling effect with respect to the conventional falling film absorber. Assume that copper flat plate collector efficiency is $100 \%$, average daily max solar insolation is $I=800 \mathrm{~W} / \mathrm{m}^{2}$; $F \tau \alpha=0.68$ and $F U=4.90\left(\mathrm{~W} / \mathrm{m}^{2}\right) /{ }^{\circ} \mathrm{C}$.

TABLE IV: SOLAR COLLECTOR SIZE

\begin{tabular}{cccccc}
\multicolumn{6}{c}{ TABLE IV: SOLAR COLLECTOR SIZE } \\
\hline \hline & $\begin{array}{c}\mathrm{T}_{\mathrm{G}} \\
\left({ }^{0} \mathrm{C}\right)\end{array}$ & $\begin{array}{c}\mathrm{T}_{\mathrm{av}} \\
\left({ }^{0} \mathrm{C}\right)\end{array}$ & $\begin{array}{c}\text { Cooling } \\
\text { effect } \\
\mathrm{QE}_{\mathrm{E}} \\
(\mathrm{kW})\end{array}$ & $\begin{array}{c}\text { Area, } \\
\mathrm{A} \\
\left(\mathrm{m}^{2} / \mathrm{kW}\right)\end{array}$ & $\begin{array}{c}\text { \%reduction of } \\
\text { Area per unit } \\
\mathrm{Q}_{\mathrm{E}}\end{array}$ \\
\cline { 1 - 3 } $\begin{array}{c}\text { With film } \\
\text { inversion }\end{array}$ & 80 & 52.7 & 1.49 & 3.5 & \\
\hline $\begin{array}{c}\text { Without } \\
\text { film } \\
\text { inversion }\end{array}$ & 90 & 62.9 & 0.56 & 10 & $65 \%$ \\
\hline \hline
\end{tabular}

\section{CONCLUSION}

The newly proposed film-inverting tubular absorber based on Coanda-effect to achieve film-inversion has shown much potential in designing a compact and low-heat driven vapour-absorption cooling system. The experimental investigation of the film-inverting hydrodynamics was performed to verify the practical feasibility. The experimental results demonstrated the feasibility of this new design. Due to the vapour absorption enhancement, increase of COP of a single-effect LiBr-absorber was found $160 \%$ higher than the absorber without any film-inversion. Besides higher cooling effect, film-inverting process helps to lower down the solution temperature to kick start vapour desorption in the generator. Such benefits are essential in designing a solar energy driven absorption cooling system by cutting down the area needed for harvesting hot water. To summarize, the proposed Coanda-effect based film-inverting absorber showed much potential for reducing the size of the absorption cooling system due to the compact assembly of absorber tubes and the lower operating temperature and pressure prevailing at the generator and condenser respectively.

\section{REFERENCES}

[1] R. Z. Wang and X. Q. Zhi, "Development of Solar thermal technologies in china," Energy, vol. 36, pp. 4407-4416, 2010.

[2] C. A. Balaras et al., "Solar air-conditioning in europe- an overview," Renewable and Sustainable Energy Reviews, vol. 1, no. 2, pp. 299-314, 2007.

[3] A. Syed et al., "A novel experimental investigation of a solar cooling system in madrid," International Journal of Refrigeration, vol. 28, no. 6, pp. 859-71, 2005.

[4] M. R. Islam, N. E. Wijeysundera, and J. C. Ho, "Performance study of a falling-film absorber with a film-inverting configuration," International Journal of Refrigeration, vol. 26, no. 8, pp. 909-917, 2003.

[5] B. S. Massey, Mechanics of Fluids, 8th Ed., Taylor and Francis Online, 2006, pp. 108-109.

[6] P. Sultana, "Study of thermal performance of falling-film absorber with and without film inversion," Ph.D. dissertation, National University of Singapore, 2006.

[7] Papia Sultana, N. E. Wijeysundera, J. C. Ho, and C. Yap, "Modeling of horizontal tube-bundle-absorbers of absorption cooling systems,", International Journal of Refrigeration, vol. 30, no. 7, pp. 709-723, 2007.

[8] M. R. Islam, "Performance evaluation of absorbers for vapor absorption cooling systems," Ph.D. dissertation, National University of Singapore, 2002.

[9] P. L. Balany, Refrigeration and Air Conditioning, Khanna Publishers, 1997. 


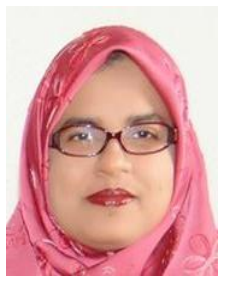

Papia Sultana received B.Sc. degree in mechanical engineering from Bangladesh University of Engineering and Technology (BUET) and Ph.D. degree from National University of Singapore (NUS) Her major field of study comprises of absorption cooling system, transport phenomena and computational fluid dynamics.

She started her career as lecturer of BUET until she joined NUS for Ph.D. in 2002. She continued to work for both Nanyang Technological University (NTU) and NUS after her Ph.D. as post doctoral fellow. She worked in the areas of district cooling, building HVAC and green building technology. She joined Republic Polytechnic,
Singapore as a faculty in 2010. She oversees the module chair role for building mechanical and electrical system. Her other teaching areas are green building design and technology, engineering design etc.

Dr Papia has achieved two internal awards for her research contribution in NUS. She has also published 5 technical papers including journals. Some of her achievements are: 1. Best paper of the year in the IJR of a young researcher- presented at the International Congress of Refrigeration in Beijing 2007 for the paper published in International Journal of Refrigeration, 2007, vol. 30, no. 7, pp 709-723. 2. Best presentation award for the outstanding paper presented in The Third Asian Conference on Refrigeration and Air-conditioning (ACRA), 2006, vol.1, pp 319-322. 